\title{
ROBUST CONTROL OF AN ISOLATED HYBRID WIND-DIESEL POWER SYSTEM USING LINEAR QUADRATIC GAUSSIAN APPROACH
}

\author{
Ahmed. M. Kassem \\ Control Technology Dep., Bini-Swief University, Egypt, \\ Email: Kassem_ahmed53@hotmail.com
}

(Received December 13, 2008 Accepted March 12, 2009)

This paper presents the application of the Linear Quadretic Gaussian $(L Q G)$ controller for voltage and frequency regulation of an isolated hybrid wind-diesel scheme. The scheme essentially consists of a vertical axis wind turbine driving a self-excited induction generator connected via an asynchronous (AC-DC-AC) link to a synchronous generator driven by a diesel engine. The synchronous generator is equipped with a voltage regulator and a static exciter. The wind generator and the synchronous generator together cater for the local load and power requirement. However, the load bus voltage and frequency are governed by the synchronous generator. The control objective aims to regulate the load voltage and frequency. This is accomplished via controlling the field voltage and rotational speed of the synchronous generator. The complete nonlinear dynamic model of the system has been described and linearized around an operating point. The standard Kalman filter technique has been employed to estimate the full states of the system. The computational burden has been minimized to a great extent by computing the optimal state feedback gains and the Kalman state space model off-line. The proposed controller has the advantages of robustness, fast response and good performance. The hybrid wind diesel energy scheme with the proposed controller has been tested through a step change in both wind speed and load impedance. Simulation results show that accurate tracking performance of the proposed hybrid wind diesel energy system has been achieved.

KEYWORDS: wind turbine, induction generator, synchronous generator, robust control and $L Q G$ control.

\section{NOMENCLATURE}

$v_{d s}, v_{q s}$ d-q stator voltages of induction generator,

$i_{d s}, i_{q s} \quad \mathrm{~d}-\mathrm{q}$ stator currents of induction generator,

$i_{d r}, i_{q r} \quad \mathrm{~d}$-q rotor currents of induction generator,

$R_{s}, R_{r} \quad$ stator and rotor resistances per phase of induction generator,

$L_{s}, L_{r}, L_{m}$ stator, rotor and magnetizing inductances of induction generator 


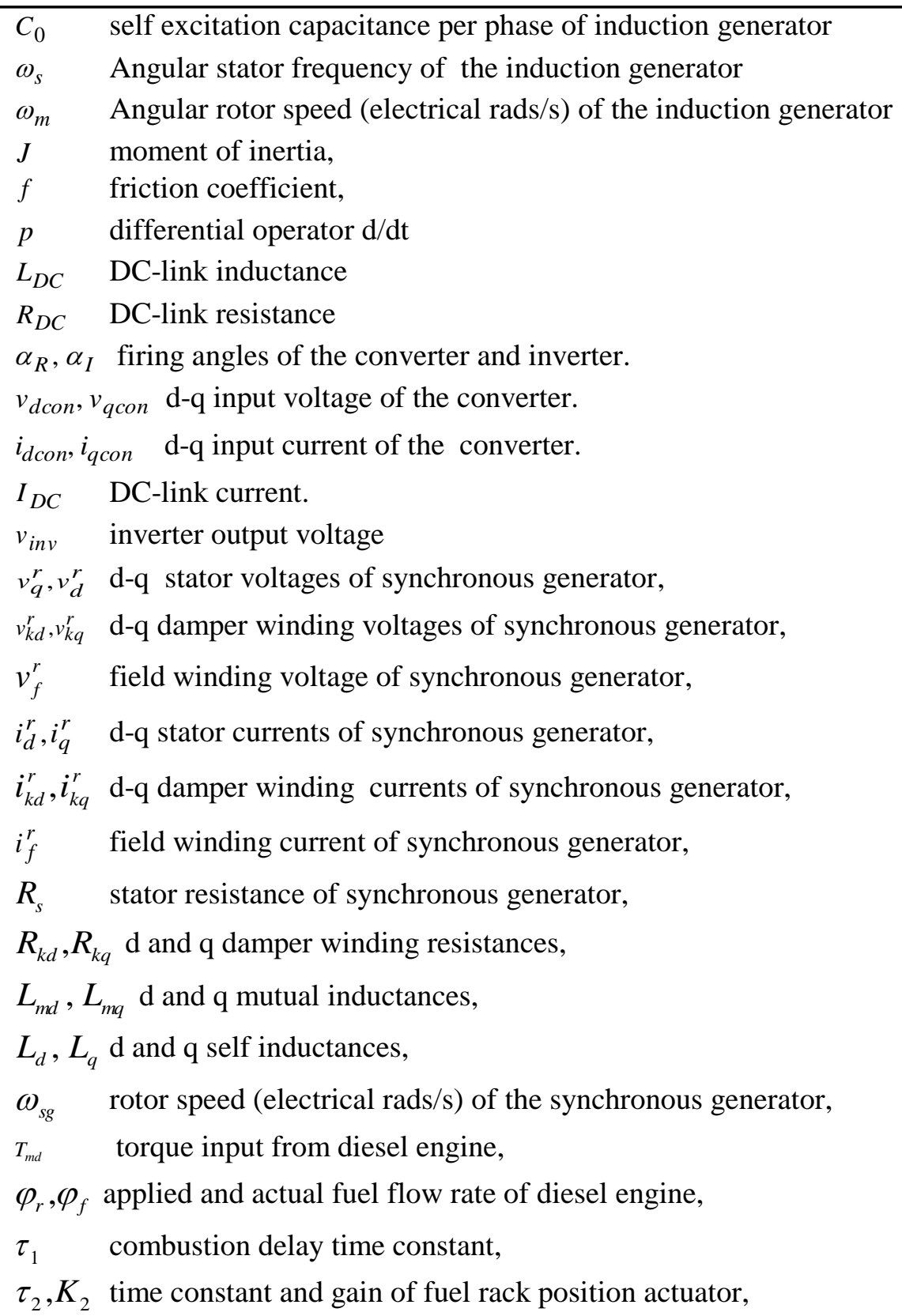

\section{INTRODUCTION}

During last three decades, the assessment of potential of the sustainable eco-friendly alternative sources and refinement in technology has taken place to a stage so that economical and reliable power can be produced. Different renewable sources are available at different geographical locations close to loads, therefore, the latest trend is to have distributed or dispersed power system. Example of such systems is wind-diesel. This system is known as hybrid power systems. 
The advantage of hybrid power systems is the combination of the continuously available diesel power and locally available, pollution-free wind energy. With the hybrid power system, the annual diesel fuel consumption can be reduced and, at the same time, the level of pollution can be minimized. A proper control strategy has to be developed to take full advantage of the wind energy during the periods of time it is available and to minimize diesel fuel consumption. Therefore, a proper control system has to be designed, subject to the specific constraints for a particular application. It has to maintain power quality, measured by the quality of electrical performance, i.e., both the voltage and the frequency have to be properly controlled [1]. These results in a need for a simulation study of each new system to confirm that a control strategy results in desired system performance.

The wind-diesel systems are normally equipped with a control system, which functions to reduce the system frequency oscillations, when the system is subjected to wind/load disturbances [2].

Various control strategies have concerned with the voltage and/or frequency control of the hybrid wind-diesel power system and achieving optimal out of the turbine. In some schemes, the hybrid wind-diesel power system uses compressed air energy storage with the wind-diesel hybrid system [3]. Other control schemes use static VAR compensators for reactive power control [4]. Mathematical modeling of a typical hybrid system with PI controllers and system dynamic studies on it has been reported by Scott [5]. However, it is well known that the performance of the systems with fixed gain controllers designed on the fixed parameter model of the system does not stay optimal as the system parameters undergo a change.

Recently, advanced control tehniques, which were applied successfully on the machine drives, have been proposed for regulating the wind power in a grid connected wind energy conversion scheme. They include Artificial neural networks [6-8], fuzzy control [7-9] and vector control [10]. In these methods, the speed feedback may be necessary to avoid instability.Moreover, wind velocity information may be needed as well. Also, the key point of direct power schemes is a correct and fast estimation of the active and reactive power as well as fast PI controllers.

In this paper, a controller design and simulations of a wind-diesel generation plant based on LQG approach are presented. This generation plant is conceived to supply electric power to an isolated load not connected to the electrical network. The main power generation system consists of a wind turbine driving a self-excited induction generator connected via an asynchronous DC link to a synchronous generator driven by a diesel engine. The synchronous generator is equipped with a voltage regulator and a static exciter. The wind generator and the synchronous generator together feed the local load.

The proposed hybrid wind diesel energy scheme with the proposed controller has been tested through a step change in both wind speed and load impedance. Simulation results show that there is accurate tracking performance of the proposed hybrid wind diesel energy system.

\section{SYSTEM DESCRIPTION}

Figure 1 shows a hybrid wind-diesel interface scheme, to supply a local isolated load. The scheme essentially consists of a vertical axis wind turbine driving a self-excited 
induction generator (SEIG) connected via an asynchronous (AC-DC-AC) link to a synchronous generator driven by a diesel engine. The synchronous generator is equipped with a voltage regulator and a static exciter. The wind generator and the synchronous generator together feed the local load power requirement.

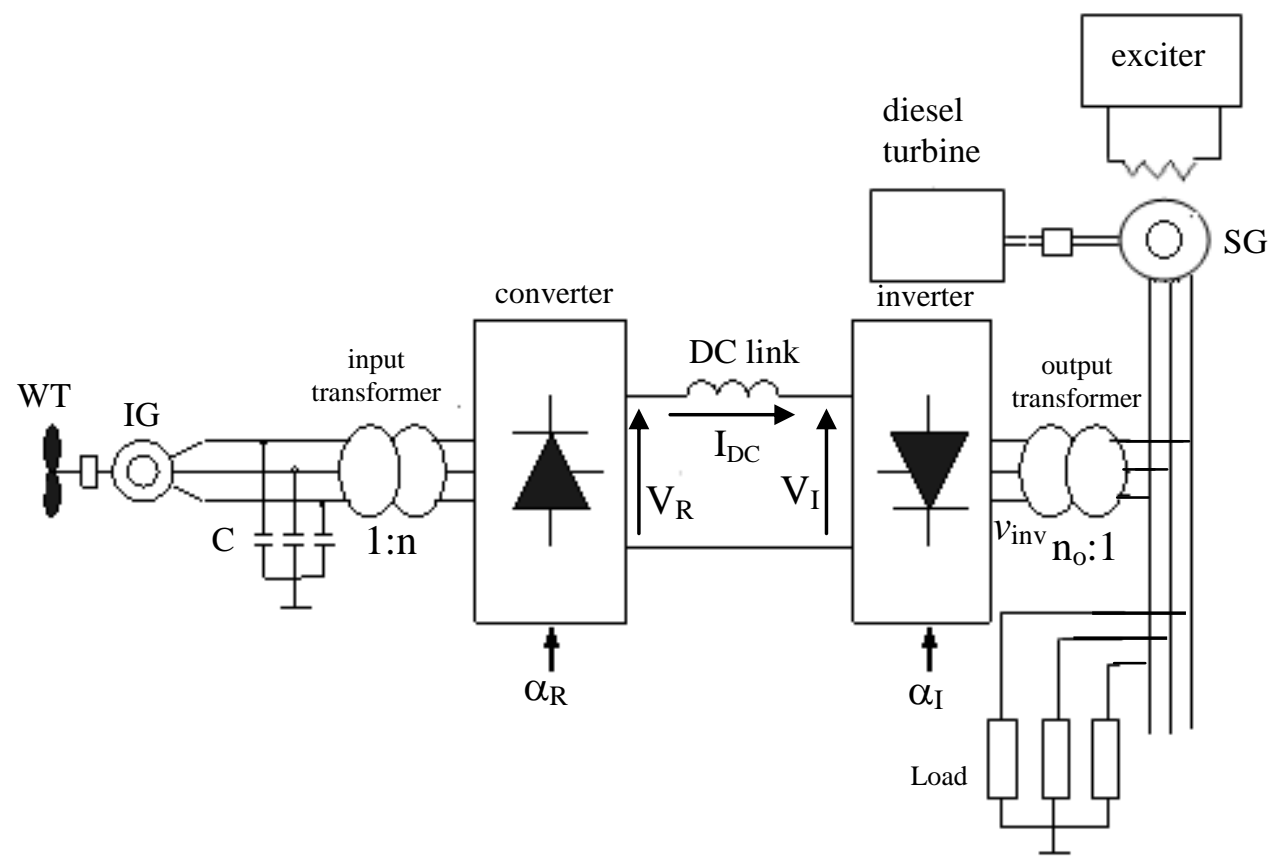

Fig. 1: Block Schematic diagram of the proposed hybrid wind-diesel-generation system.

\section{SYSTEM DYNAMIC MODEL}

The dynamic models of the different parts of the system can be described as follows:

\subsection{Wind Side Dynamic Model}

The wind side system is consists of wind turbine, induction generator and DC-Link which can model as following:

\subsection{Wind turbine Dynamic Model}

The wind turbine is characterized by no dimensional curves of the power coefficient $C_{p}$ as a function of both the tip speed ratio, $\lambda$ and the blade pitch angle, $\beta$. In order to fully utilize the available wind energy, the value of $\lambda$ should be maintained at its optimum value. Hence, the power coefficient corresponding to that value will become maximum also.

The tip speed ratio $\lambda$ can be defined as the ratio of the angular rotor speed of the wind turbine to the linear wind speed at the tip of the blades. It can be expressed as follows: 


$$
\lambda=\omega_{t} R / V_{w}
$$

Where $R$ is the wind turbine rotor radius, $V_{w}$ is the wind speed and $\omega_{t}$ is the mechanical angular rotor speed of the wind turbine.

The torque available from the wind turbine can be expressed as [11] :

$T_{m}=0.5 \rho A R\left[(0.44-0.0167) \beta \sin \left(\frac{\frac{\omega_{t} R}{V_{w}}-3}{15-0.3 \beta}\right)-0.00184\left(\frac{\omega_{t} R}{V_{w}}-3\right) \beta\right] V_{w}^{3} / \omega_{t}$

Where $\rho$ is the air density, and $A$ is the swept area by the blades.

\subsubsection{Induction Generator Dynamic Model}

The dynamic behavior of the induction generator in the $\mathrm{d}-\mathrm{q}$ axis synchronously rotating reference frame is given by [12]:

$$
\begin{aligned}
& p i_{q s}=-R_{s} A_{1} i_{q s}-\left(\omega_{s}+A_{2} \omega_{m} L_{m}\right) i_{d s}+R_{r} A_{2} i_{q r}-A_{1} \omega_{m} L_{r} i_{d r} \\
& p i_{d s}=\left(\omega_{s}+A_{2} \omega_{m} L_{m}\right) i_{q s}-R_{s} A_{1} i_{d s}+R_{r} A_{2} i_{d r}+A_{1} \omega_{m} L_{m} i_{q r}-A_{1} v_{d s} \ldots \ldots \ldots \ldots \ldots \ldots \ldots \ldots \\
& p i_{q r}=R_{s} A_{2} i_{q s}+A_{2} \omega_{m} L_{s} i_{d s}-A_{3} i_{q r}+\left(-\omega_{s}+A_{1} \omega_{m} L_{s}\right) i_{d r}
\end{aligned}
$$

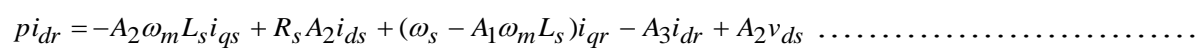

Where $v_{q s}=0$, due to the choice of axis alignment, and

$A_{1}=L_{r} /\left(L_{S} L_{r}-L_{m}^{2}\right), \quad A_{2}=L_{m} /\left(L_{S} L_{r}-L_{m}^{2}\right)$,

and $A_{3}=R_{r}\left(1+A_{2} L_{m}\right) / L_{r}$

The rotor speed $\omega_{m}$ is governed by the following differential equation:

$T_{m}+T_{e}=(J p+f) \omega_{m} / P$

Where $\mathrm{P}$ is number of poles of the induction generator, $T_{m}$ is the input torque from the prim-mover, and $T_{e}$ is the electromagnetic torque representing the load on the induction generator ( $T_{e}$ is negative for generator action) which is given by :

$T_{e}=1.5 P L_{m}\left(i_{q s} i_{d r}-i_{d s} i_{q r}\right)$

Equations (9) and (10) are combined as

$p \omega_{m}=\left(-f \omega_{m}+P T_{m}+1.5 P^{2} L_{m}\left(i_{q s} i_{d r}-i_{d s} i_{q r}\right)\right) / J$

\subsubsection{Asynchronous DC Link Model}

The asynchronous DC link (used to interface the wind energy system to the utility ) consists of a six pulse line commutated converter, a smoothing reactor, and a six pulse line commutated inverter. An isolating transformer of turns ratio $1: n$ interconnects the induction generator to the converter. Neglecting the resistance and leakage reactance of the isolating transformer, the various ac quantities on the primary and secondary sides can be related by:

$$
v_{d c o n}=n v_{d s}, \quad v_{q c o n}=n v_{q s}, \quad i_{q c o n}=i_{q l} / n, i_{d c o n}=i_{d l} / n
$$

Assuming the converter is lossless, the instantaneous power balance equation $\left(v_{q c o n}=0\right.$, due to the choice of axis alignment) : 
$\frac{3}{2} v_{d c o n} i_{d c o n}=V_{R} I_{D C}$

Where $V_{R}$ is the DC voltage at the converter output terminals which can be written as :

$V_{R}=\frac{3 \sqrt{3}}{\pi} n v_{d s} \cos \alpha_{R}$

The ac and dc currents of the converter are related by :

$i_{c o n}=\sqrt{\left(i_{q c o n}^{2}+i_{d c o n}^{2}\right)}=\frac{2 \sqrt{3}}{\pi} I_{D C}$

Neglecting the commutation overlap, the d-q converter currents can be deduced using equations (13-15) as :

$i_{d c o n}=i_{c o n} \cos \alpha_{R}=\frac{2 \sqrt{3}}{\pi} I_{D C} \cos \alpha_{R}$
$i_{q c o n}=-i_{c o n} \sin \alpha_{R}=-\frac{2 \sqrt{3}}{\pi} I_{D C} \sin \alpha_{R}$

Referring to Fig. 1, the dynamics introduced by the DC link is given by:

$L_{D C} P I_{D C}+R_{D C} I_{D C}=V_{R}-V_{I}$

Where $V_{I}$ is the DC voltage at the inverter input terminals which can be expressed as:

$V_{I}=-\frac{3 \sqrt{3}}{\pi} v_{i n v} \cos \alpha_{I}+\frac{3 x_{c i}}{\pi} I_{D C}$

where $x_{c i}$ is the commutating reactance.

Combining equations (12), (17), and (18) the following equation can be obtained :

$p I_{D C}=\left(-R_{D C} I_{D C}+\frac{3 \sqrt{3}}{\pi} n v_{d s} \cos \alpha_{R}+\frac{3 \sqrt{3}}{\pi} v_{i n v} \cos \alpha_{I}-\frac{3 x_{c i}}{\pi} I_{D C}\right) / L_{D C}$

$p I_{D C}=\left(\begin{array}{l}\left(-R_{D C}-\frac{3 x_{c i}}{\pi}-\frac{18 R_{L}}{\pi^{2}}\left(\cos \left(\alpha_{I}\right)^{2}-\frac{18 \omega_{e} L_{L}}{\pi^{2}}\left(\sin \left(\alpha_{I}\right)^{2}\right) I_{D C}\right.\right. \\ +\frac{3 \sqrt{3}}{\pi} n \cos \alpha_{R} v_{d s}+\frac{3 \sqrt{3} n_{o}}{\pi} \cos \alpha_{I}\left(\begin{array}{c}i_{q}^{r} \cos (\delta)+i_{d}^{r} \sin (\delta) \\ -i_{q}^{r} \sin (\delta)+i_{d}^{r} \cos (\delta)\end{array}\right)\end{array}\right) / L_{D C}$

\subsubsection{Self Excitation Capacitor Model}

Referring to the d-q equivalent circuit of the self excitation capacitor shown in Fig. 2, the following differential equations can be written:

$p v_{q s}=\frac{i_{q c}}{C_{0}}-\omega_{s} v_{d s}$

$p v_{d s}=\frac{i_{d c}}{C_{0}}+\omega_{s} v_{q s}$

Since, $v_{q s}=0$, due to the choice of axis alignment, equations (21-22) can be rewritten as:

$\omega_{s}=\frac{i_{q c}}{C_{0} v_{d s}}$

$p v_{d s}=\frac{i_{d c}}{C_{0}}$ 

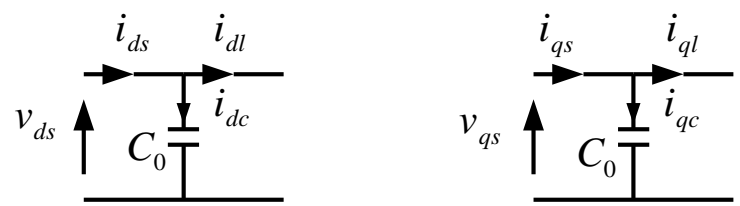

Fig. 2 : d-q equivalent circuit of the self excitation capacitor

Referring to Fig. 2, the values of $i_{q c}$ and $i_{d c}$ can be written as:

$i_{q c}=i_{q s}-i_{q l}, \quad i_{d c}=i_{d s}-i_{d l}$

Equations $(12,15$ and 16) are combined with equation (25) as:

$i_{q c}=i_{q s}+\frac{2 \sqrt{3}}{\pi} n I_{D C} \sin \alpha_{R}, i_{d c}=i_{d s}-\frac{2 \sqrt{3}}{\pi} n I_{D C} \cos \alpha_{R}$

Substituting the values of $i_{q c}$ and $i_{d c}$ from equation (26) into equations (23) and (24) would give:

$$
\begin{aligned}
& \omega_{s}=\frac{i_{q s}+\frac{2 \sqrt{3}}{\pi} n I_{D C} \sin \alpha_{R}}{C_{0} v_{d s}} \\
& p v_{d s}=\frac{i_{d s}-\frac{2 \sqrt{3}}{\pi} n I_{D C} \cos \alpha_{R}}{C_{0}}
\end{aligned}
$$

Equation (27) can be used to determine the electrical frequency of the voltage generated by the induction generator.

\subsection{Diesel Side Dynamic Model}

Diesel side system consists of diesel engine, synchronous generator and the load which can modeled as following:

\subsubsection{Synchronous Generator Dynamic Modeling}

The dynamic behavior of the synchronous generator in the $\mathrm{d}^{\mathrm{r}}-\mathrm{q}^{\mathrm{r}}$ axis synchronously rotating reference frame fixed in the rotor (i.e., $\mathrm{d}^{\mathrm{r}}-\mathrm{q}^{\mathrm{r}}$ reference frame rotating at the rotor speed $\omega_{\mathrm{sg}}$ ) is given by [12]:

$$
\begin{aligned}
& p i_{q}^{r}=\frac{\dot{L}_{k q}^{\prime}}{\left(L_{k q}^{\prime}-L_{m q}^{2}\right.}\left[-R_{s} r_{q}^{r}-\frac{\dot{L}_{k q}^{\prime} L_{m q}^{\prime}}{L_{k q}^{\prime}} i_{k q}^{r^{\prime}}-\omega_{s g} r_{d}^{r}+\omega_{s g} L_{m d} i_{k d}^{r^{\prime}}+\omega_{s g} L_{m d} i_{f}^{r^{\prime}}-V_{q}^{r}\right] \ldots \ldots \ldots \\
& p i_{d}^{r}=\frac{1}{K_{11}}\left[\begin{array}{l}
\omega_{s s} L_{q} i_{q}^{r}-R_{s} i_{d}^{r}-\omega_{s g} L_{m q} r_{k q}^{r_{k q}^{\prime}} \\
+\left(K_{22} R_{k d}^{\prime} L_{f}^{\prime}+K_{33} R_{k d}^{\prime} L_{m d}\right) v_{k d}^{r^{\prime}} \\
-\left(K_{22} L_{m d}+K_{33} L_{k d}^{\prime}\right) R_{f}^{\prime} i_{f}^{r^{\prime}} \\
+\left(K_{22} L_{m d}+K_{33} L_{k d}^{\prime}\right) v_{f}^{r^{\prime}}-v_{d}^{r^{r}}
\end{array}\right] \\
& p i_{k q}^{r^{\prime}}=-\frac{R_{k q}^{\prime}}{L_{k q}^{\prime}} i_{k q}^{r^{\prime}}+K_{44}\left[\begin{array}{l}
-R_{s} i_{q}^{r}-\frac{R_{k q}^{\prime} L_{m q}}{L_{k q}^{\prime}} i_{k q}^{r^{\prime}}-\omega_{s g} L_{d} i_{d}^{r} \\
+\omega_{s g} L_{m d} i_{k d}^{r^{\prime}}+\omega_{s g} L_{m d} i_{f}^{r^{\prime}}-v_{q}^{r}
\end{array}\right]
\end{aligned}
$$




$$
\begin{aligned}
& p i_{k d}^{r^{\prime}}=K_{22}\left[\begin{array}{c}
v_{f}^{r^{\prime}}+\frac{\left(L_{m d}-L_{f}^{\prime}\right)}{K_{11}}\left(\begin{array}{l}
\omega_{s g} L_{q} i_{q}^{r}-R_{s} i_{d}^{r}-\omega_{s g} L_{m q} i_{k q}^{r^{\prime}} \\
+\left(K_{22} L_{f}^{\prime} R_{k d}^{\prime}+K_{33} L_{m d} R_{k d}^{\prime}\right) i_{k d}^{r^{\prime}} \\
-\left(K_{22} L_{m d} R_{k d}^{\prime}+K_{33} L_{k d}^{\prime}\right) R_{f}^{\prime} i_{f}^{r^{\prime}} \\
+\left(K_{22} L_{m d} R_{k d}^{\prime}+K_{33} L_{k d}^{\prime}\right) v_{f}^{r^{\prime}}-v_{d}^{r}
\end{array}\right) \\
+\frac{R_{k d}^{\prime} L_{f}^{\prime}}{L_{m d}} i_{k d}^{r^{\prime}}-R_{f}^{\prime} i_{f}^{r^{\prime}}
\end{array}\right] \\
& p i_{f}^{r^{\prime}}=\frac{L_{k d}^{\prime}}{L_{m d}} K_{33}\left[v_{f}^{r^{\prime}}+\frac{1}{K_{11} K_{55}}\left(\begin{array}{l}
\omega_{s g} L_{q} i_{q}^{r}-R_{s} i_{d}^{r}-\omega_{s g} L_{m q} r_{k q}^{r^{\prime}} \\
+\left(K_{22} L_{f}^{\prime} R_{k d}^{\prime}+K_{33} L_{m d} R_{k d}^{\prime}\right) i_{k d}^{r^{\prime}} \\
-\left(K_{22} L_{m d}+K_{33} L_{k d}^{\prime}\right) R_{f}^{\prime} i_{f}^{r^{\prime}} \\
+\left(K_{22} L_{f}^{\prime} R_{k d}^{\prime}+K_{33} L_{m d} R_{k d}^{\prime}\right) v_{f}^{r^{\prime}}-v_{d}^{r}
\end{array}\right)\right] \ldots \ldots
\end{aligned}
$$

Where

$$
\begin{aligned}
& K_{11}=L_{d}-\frac{L_{m d}^{2}\left(L_{m d}-L_{f}^{\prime}\right)}{\left(L_{m d}^{2}-L_{f}^{\prime} L_{k d}^{\prime}\right)}-\frac{L_{m d}\left(L_{m d} L_{k d}^{\prime}-L_{m d}^{2}\right)}{\left(L_{f}^{\prime} L_{k d}^{\prime}-L_{m d}^{2}\right)} \\
& \left.K_{22}=\frac{L_{m d}}{\left(L_{m d}^{2}-L_{f}^{\prime} L_{k d}^{\prime}\right)}, \quad K_{33}=\frac{L_{m d}}{\left(L_{f}^{\prime} L_{k d}^{\prime}-L_{m d}^{2}\right)}, \quad K_{44}=\frac{L_{m q}}{\left(L_{q} L_{k q}^{\prime}-L_{m q}^{2}\right.}\right), \quad K_{55}=\frac{L_{k d}^{\prime}}{\left(L_{m d} L_{k d}^{\prime}-L_{m d}^{2}\right.},
\end{aligned}
$$

The $\mathrm{q}^{\mathrm{r}}$ and $\mathrm{d}^{\mathrm{r}}$ stator voltages in the reference frame fixed in the rotor are given by:

$$
\begin{aligned}
& v_{q}^{r}=-i_{q}^{r} R_{s}-\omega_{s g} L_{d} i_{d}^{r}+\omega_{s g} L_{m d} i_{k d}^{r^{\prime}}+\omega_{s g} L_{m d} i_{f}^{r^{\prime}} \\
& v_{d}^{r}=-i_{d}^{r} R_{s}+\omega_{s g} L_{q} i_{q}^{r}-\omega_{s g} L_{m q} i_{k q}^{r^{\prime}}
\end{aligned}
$$

The rotor speed $\mathrm{w}_{\mathrm{sg}}$ is governed by the following differential equation:

$$
\frac{2}{p_{o}}\left(J p \omega_{s g}+f \omega_{s g}\right)=T_{m d}-T_{e}
$$

Where, $\mathrm{P}_{\mathrm{o}}$ is the number of poles of synchronous generator, $\mathrm{T}_{\mathrm{md}}$ is the input torque from the prime mover (diesel engine) and $\mathrm{T}_{\mathrm{e}}$ is the electromagnetic torque representing the electrical load on the synchronous generator and is given by :

$$
T_{e}=\left(\frac{3}{2}\right)\left(\frac{p_{o}}{2}\right)\left[L_{m d}\left(-i_{d}^{r}+i_{f}^{r^{\prime}}+i_{k d}^{r^{\prime}}\right) i_{q}^{r}-L_{m q}\left(-i_{q}^{r}+i_{k q}^{r^{\prime}}\right) i_{d}^{r}\right]
$$

Lastly, the torque angle representing the electrical load on the synchronous generator is given by:

$$
p \delta=\frac{2}{p_{o}}\left(\omega_{s g}-\omega_{e}\right)+\delta_{o}
$$

Where $\mathrm{w}_{\mathrm{sg}}$ and $\mathrm{w}_{\mathrm{e}}$ are the synchronous generator's rotor speed and electrical frequency respectively and $\delta_{\mathrm{o}}$ is the initial torque angle. In steady state, $\mathrm{w}_{\mathrm{sg}}$ and $\mathrm{w}_{\mathrm{e}}$ are the same, but during transient $\mathrm{w}_{\mathrm{sg}}$ changes and ultimately settles down to the value $\mathrm{w}_{\mathrm{e}}$. The $v_{q}^{e}$ and $v_{d}^{e}$ stator voltages in the reference frame fixed with the synchronously rotating frame MMF vector rotating at an angular velocity $\omega_{\mathrm{e}}$ are given by:

$$
\begin{aligned}
& v_{q}^{e}=v_{q}^{r} \cos (\delta)+v_{d}^{r} \sin (\delta) \\
& v_{d}^{e}=-v_{q}^{r} \sin (\delta)+v_{d}^{r} \cos (\delta)=0 \\
& v_{L}=\sqrt{\left(v_{q}^{e}\right)^{2}+\left(v_{d}^{e}\right)^{2}}=v_{q}^{e}
\end{aligned}
$$


The initial orientation of $\mathrm{q}$ and $\mathrm{d}$ reference frame is chosen such that $v_{d}^{e}$ is initially zero and the load voltage $\mathrm{V}_{\mathrm{L}}=v_{q}^{e}$.

\subsubsection{Voltage Regulator and Static Exciter Model}

The voltage and frequency at the local load bus are set by the synchronous generator. Under load excursion, the load voltage tends to vary. In order to regulate the bus voltage, the synchronous generator is equipped with an automatic voltage regulator (AVR) and a static exciter [12]. The static exciter is an "inverted" three phase generator, with the automatic windings on the rotor and the field windings on the stator. The AC armature voltage is rectified using diodes mounted on the rotating shaft, and the rectified voltage is applied to the synchronous generator field as shown in fig. 3. The differential equations describing the excitation system for the synchronous generator are as follows:

$$
\begin{aligned}
& p v_{c}=\left(V_{\text {Lref }}-V_{L}\right)=V_{\text {ref }}-\left\{\begin{array}{l}
R_{L}\left(i_{q}^{r} \cos (\delta)+i_{d}^{r} \sin (\delta)-\frac{2 \sqrt{3}}{\pi n_{o}} I_{D C} \cos \left(\alpha_{i}\right)\right) \\
+\omega_{e} L_{L}\left(-i_{q}^{r} \sin (\delta)+i_{d}^{r} \cos (\delta)-\frac{2 \sqrt{3}}{\pi n_{o}} I_{D C} \sin \left(\alpha_{i}\right)\right)
\end{array}\right\} \\
& p v_{f}^{\prime}=\frac{K_{e} v_{C}-v_{f}^{\prime}}{\tau_{e}}
\end{aligned}
$$

Where, $\mathrm{K}_{\mathrm{e}}$ is the gain of the exciter and $\tau_{\mathrm{e}}$ is the time constant of the exciter.

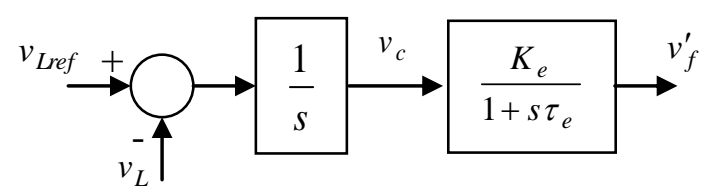

Fig. 3: Static voltage regulator loop

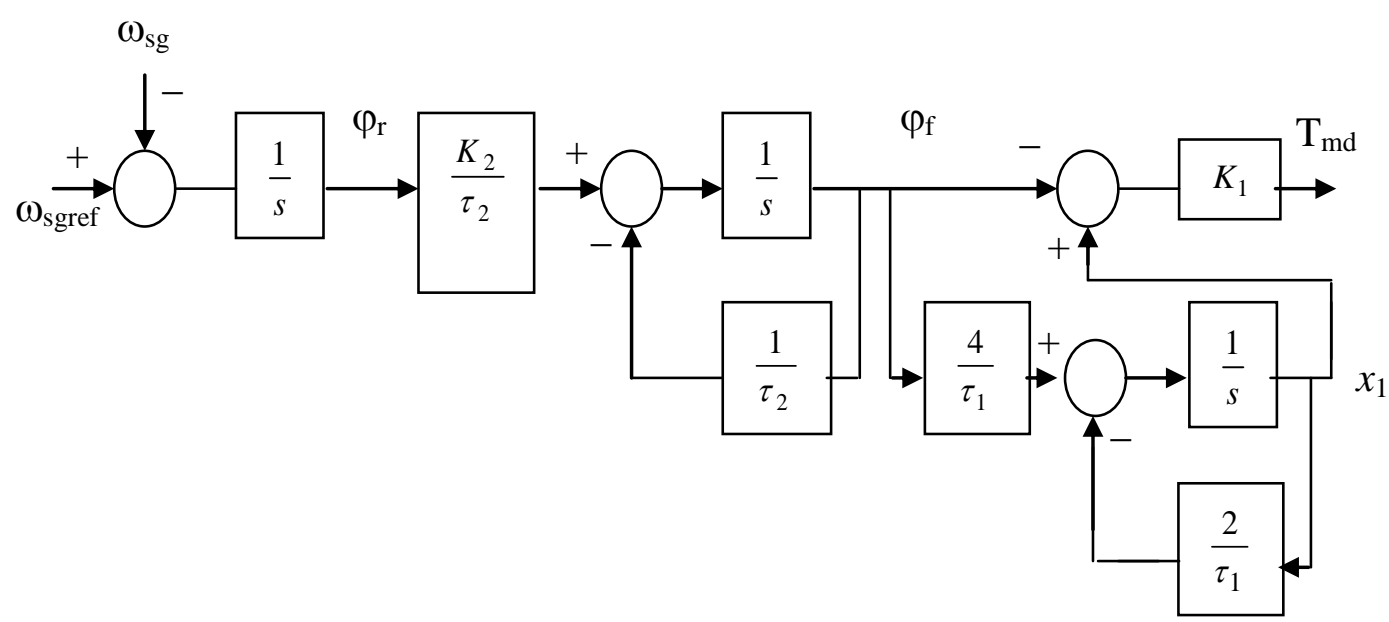

Fig.4: State space representation of diesel engine and speed regulator loop 


\subsubsection{Speed Regulator And Diesel Engine Model}

The synchronous generator is driven by a diesel engine which controls the mechanical power input to the generator to balance the electrical load on the machine. If the electrical load on the generator changes due to change in power drawn by the local load, the rotor speed and hence the electrical frequency tend to change. In such a situation the mechanical power (or torque) input to the synchronous generator is controlled to regulate the system electrical frequency. The block diagram of the diesel engine is shown in fig. 4 [12]. The input signal is the speed (frequency) error and is used to determine the applied fuel flow rate $\varphi_{\mathrm{r}}$ depending on the position of the fuel rack which is controlled by the fuel actuator, characterized by a gain $\mathrm{k}_{2}$ and a time constant $\tau_{2}$. The torque output $\mathrm{T}_{\mathrm{md}}$ of the diesel engine is proportional to the actual fuel flow rate $\varphi_{\mathrm{f}}$, but is delayed by the fuel combustion process time delay $\tau_{1}$. The torque output of the diesel engine is:

$T_{m d}=K_{1} \phi_{f} e^{-\tau_{1} s}$

Where $\mathrm{K}_{1}$ is constant relating the torque output to the fuel flow rate. The combustion process delay can be approximated using first order Pad's approximation as follows:

$e^{-\tau_{1} s}=\frac{\left(\frac{2}{\tau_{1}}-s\right)}{\left(\frac{2}{\tau_{1}}+s\right)}$

The actual fuel flow rate $\varphi_{f}$ is dependent on the applied fuel flow rate $\varphi_{r}$ and is given by:

$$
\varphi_{f}=\frac{K_{2}}{\left(1+\tau_{2} s\right)} \varphi_{r}
$$

Where $K_{2}$ and $\tau_{2}$ are gain and time constant of the fuel actuator. The differential equations describing the diesel engine and its speed governor are given by [12]:

$$
\begin{aligned}
& p \varphi_{r}=\omega_{s g r e f}-\omega_{s g} \\
& p \varphi_{f}=\frac{K_{2} \varphi_{r}-\varphi_{f}}{\tau_{2}} \\
& p x_{1}=\frac{4 \varphi_{f}-2 x_{1}}{\tau_{1}} \\
& T_{m d}=K_{1}\left(x_{1}-\varphi_{f}\right)
\end{aligned}
$$

\subsection{Small Signal Linearized model}

The subsystem models can be interfaced to form the unified nonlinear model.

The nonlinear model of the hybrid wind-diesel-generation system are linearized around an operating point as following:

$\mathrm{px}=\mathrm{A} \mathrm{x}+\mathrm{B} \mu+\mathrm{vd}$

Where

$x=\left[\begin{array}{ll}X_{1} & X_{2}\end{array}\right]$

and

$$
\begin{aligned}
X_{1} & =\left[\begin{array}{llllllllll}
\Delta i_{q s} & \Delta i_{d s} & \Delta i_{q r} & \Delta i_{d r} & \Delta \omega_{m} & \Delta v_{d s} & \Delta I_{D C} & \Delta i_{q}^{r} & \Delta i_{d}^{r} & \Delta i_{k q}^{r}
\end{array}\right] \\
X_{2} & =\left[\begin{array}{lllllllll}
\Delta i_{k d}^{r} & \Delta i_{f}^{r} & \Delta \omega_{s g} & \Delta \delta & \Delta V_{c} & \Delta V_{f}^{\prime} & \Delta \varphi_{r} & \Delta \varphi_{f} & \Delta x_{1}
\end{array}\right]
\end{aligned}
$$


$\mu=\left[\begin{array}{ll}V_{\text {Lref }} & \omega_{\text {sgref }}\end{array}\right]^{t}$

$d=\left[\begin{array}{ll}\Delta Z_{L} & V_{w}\end{array}\right]$

$\mathrm{A}=\left[a_{i j}\right]$ is a $19 \times 19$ matrix.

\section{CONTROL STRATEGY}

In this paper, the LQG controller has been employed to control the terminal voltage and frequency of an isolated hybrid wind-diesel generation unit. The LQG is a modern state space technique for designing optimal dynamic regulators. It has the following advantages:

1) It enables to trade off regulation performance and control effort.

2) It takes into account the process disturbance and measurement noise.

The LQG controller consists of an optimal state feedback gain " $k$ " and a Kalman state estimator. The optimal feedback gain is calculated such that the feedback control law

$u=-k x$

minimizes the performance index :

$H=\int_{0}^{\infty}\left(x^{T} Q x+u^{T} R u\right) d t$

where $Q$ and $R$ are positive definite or semi definite Hermittian or real symmetric matrices. The optimal state feedback $\mathrm{u}=-\mathrm{kx}$ is not implemental without full state measurement. In our case, the load current only is chosen to be the output measured signal. The Kalman filter estimator is used to drive the state estimation:

$\hat{x}=\left[\begin{array}{ll}\hat{X}_{1} & \hat{X}_{2}\end{array}\right]$

and

$\hat{X}_{1}=\left[\begin{array}{llllllllll}\Delta \hat{i}_{q s} & \Delta \hat{i}_{d s} & \Delta \hat{i}_{q r} & \Delta \hat{i}_{d r} & \Delta \hat{\omega}_{m} & \Delta \hat{v}_{d s} & \Delta \hat{I}_{D C} & \Delta \hat{i}_{q}^{r} & \Delta \hat{i}_{d}^{r} & \Delta \hat{i}_{k q}^{r}\end{array}\right]$

$\hat{X}_{2}=\left[\begin{array}{lllllllll}\Delta \hat{i}_{k d}^{r} & \Delta \hat{i}_{f}^{r} & \Delta \hat{\omega}_{s g} & \Delta \hat{\delta} & \Delta \hat{V}_{c} & \Delta \hat{V}_{f}^{\prime} & \Delta \hat{\varphi}_{r} & \Delta \hat{\varphi}_{f} & \Delta \hat{x}_{1}\end{array}\right]$

such that

$u=-k \hat{x}$

remains optimal for the output feedback problem. The state estimation is generated from [16]:

$P=(A-B k-L C) \hat{x}+L y$

Where $\mathrm{L}$ is the Kalman gain which is determined by knowing the system noise and choosing $Q_{n}$ and $R_{n}$. However, the accuracy of the filter's performance depends heavily upon the accuracy of this covariance. On the other hand the matrices $A$ and $B$ containing the hybrid wind diesel generation system parameters are not required to be very accurate due to the inherent feedback nature of the system. The Kalman filter performs best for linear systems. Therefore, the nonlinear model of the complete system has been linearized around an operating point. The optimal state feedback gains and the Kalman state space model have been calculated offline which results in great saving in computational burden. On this basis, the implementation of the proposed controller becomes easier and the hardware will be reduced to minimum. 


\section{SYSTEM CONFIGURATION}

The block diagram of the isolated hybrid wind-diesel generation system with the proposed LQG controller is shown in Fig. 5. All the commanded values are superscripted with asterisk in the diagram. The LQG controller contains the Kalman state estimator in addition to optimal state feedback gains. The Kalman estimator uses both the measured $\mathrm{d}-\mathrm{q}$ stator current components of induction generator and synchronous generator in order to estimate all the states including the d-q rotor current components of synchronous generator, generator speed of induction and synchronous machines, d-axis generated voltage at induction generator, DC link current, damper and field currents of synchronous generator, fuel flow rate of diesel engine. These states are multiplied by the corresponding optimal gains and summed to produce the control signals necessary to regulate the field voltage and the shaft rotational speed of the synchronous generator.

The entire system has been simulated on the digital computer using the Matlab/Simulink software package. The specifications of the system used in the simulation procedure are listed in appendix [12].

The noise and measurement covariance are set as :

$$
Q_{n}=\operatorname{diag}(10,10) \quad, R_{n}=\operatorname{diag}(1,1)
$$

Also, the values of $Q$ and $R$ matrices which are necessary to calculate the optimal feedback gains are set as :

$Q=\operatorname{diag}(2001010101001010101010010101010101010101000)$, $R=\operatorname{diag}(2.052 .05)$.

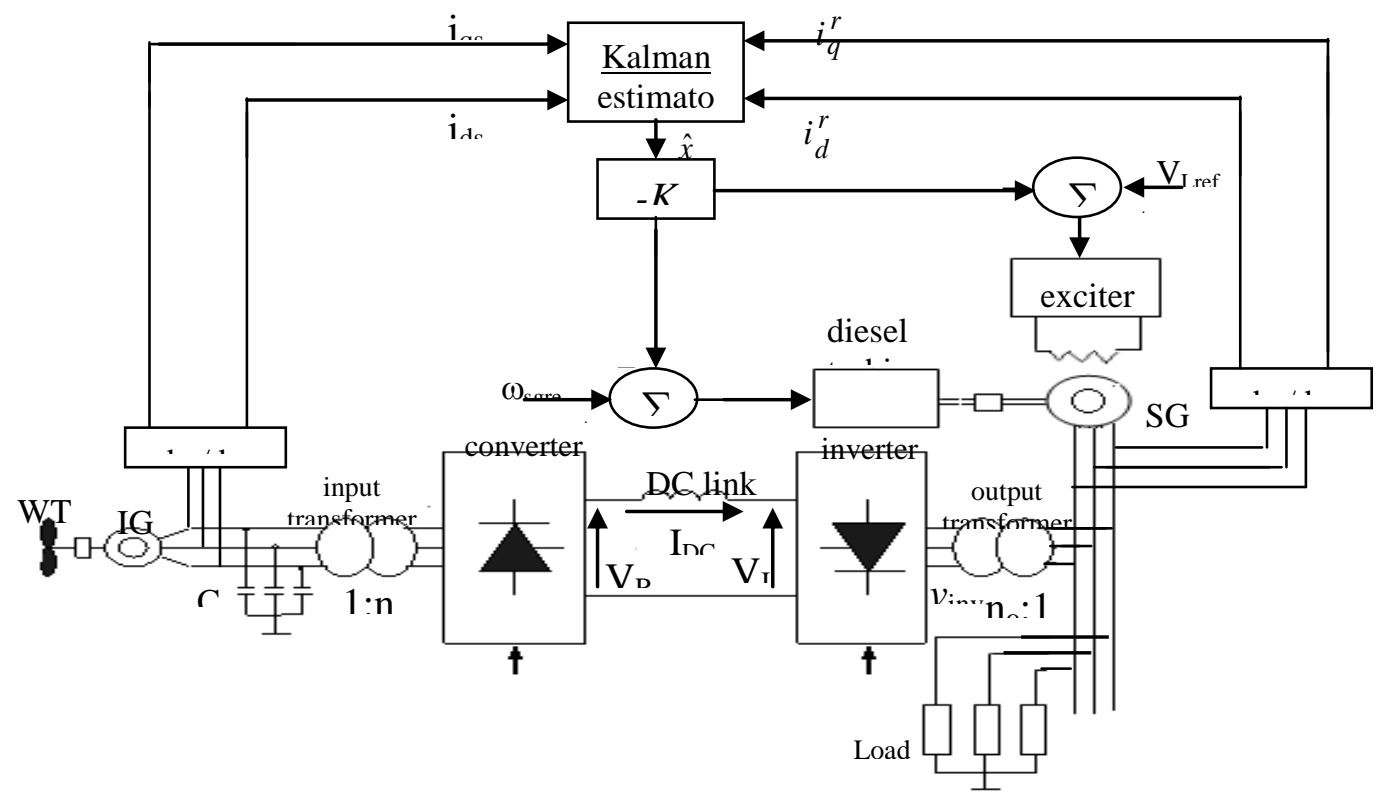

Fig. 5: Block diagram of the hybrid wind-diesel generation power system with the proposed LQG controller 


\section{SIMULATION RESULTS}

Digital simulations have been carried out to validate the effectiveness of the proposed system under wind speed and load variations. The performance of the proposed scheme has been tested with a step changes in both wind speed and load impedance.

The simulation results depicting the variations in various variables with a step change in local load impedance is shown in Fig. 6. It is seen that as the local load impedance increases (the local current decrease), with wind velocity remaining constant, so the rotor speed of the synchronous generator tries to increase. The control action comes in operation and decreases the power output of the synchronous generator to meet the decreased power demand of the load. This is achieved by decreasing the diesel fuel rate $\phi_{\mathrm{f}}$ which in turn decreases the torque (mechanical power) to the synchronous generator. Also, the field current is decreased to regulate the local bus voltage and the opposite will happen when the local impedance decreases.

The effect of variations in wind velocity on the various system variables are shown in Fig. 7. It seen that with increase in wind velocity (this means that the power contributed by the inverter increases) and hence the load voltage and current increase. So the same as the case of load impedance reduction, the controller comes in operation and reduces the diesel fuel rate $\phi f$ which in turn decreases the torque (mechanical power) to the synchronous generator. Also the field current of the synchronous generator decreases. That leads to adjusting the load voltage and frequency and vice versa if the wind speed decreases. It is also seen that the damper winding current only comes into play during the initial transients, and reduces to zero subsequently. Simulation results indicate that a hybrid wind-diesel scheme can be adequately controlled and the local bus voltage and frequency can be regulated by the use of AVR and a diesel engine with robust LQG control.

\section{CONCLUSIONS}

This paper investigates the robust control of an isolated wind-diesel generation system based on the LQG approach. The controlled system consists of a diesel engine that drives a synchronous generator connected to an isolated load and the synchronous generator is equipped with an automatic voltage regulator (AVR) and a static exciter and also wind turbine driven SEIG, which interfaced to the load bus through DC-link. A complete model, control design and simulations of this scheme have been developed showing the ability of the controller to compensate both the wind power oscillations and load disturbances. The local load bus voltage and frequency are governed by the synchronous machine. The load bus voltage is regulated via controlling the field current of the synchronous generator. Also, the load bus frequency is adjusted by controlling the rotor speed of the synchronous generator which is adjusted by controlling the diesel fuel flow rate $\varphi_{\mathrm{r}}$ which in turn affects the torque (mechanical power) input to the synchronous generator and hence its rotation speed. The standard Kalman filter technique has been used to estimate the full states of the system by measuring only the currents of both induction and synchronous generators. The proposed controller has the advantages of robustness, easy implementation and adequate performance in face of uncertainties. 

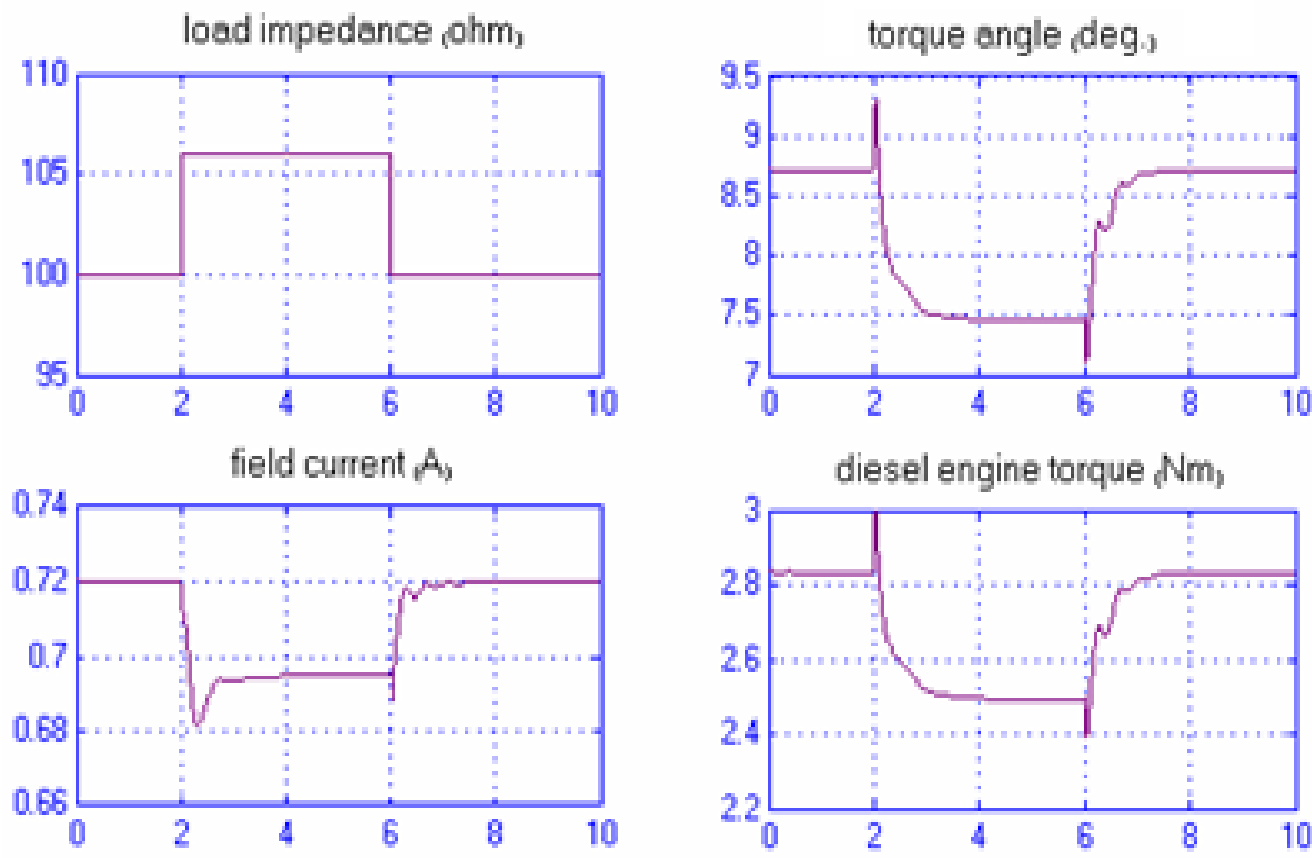

diesel engine torque $\mathrm{Nm}$,
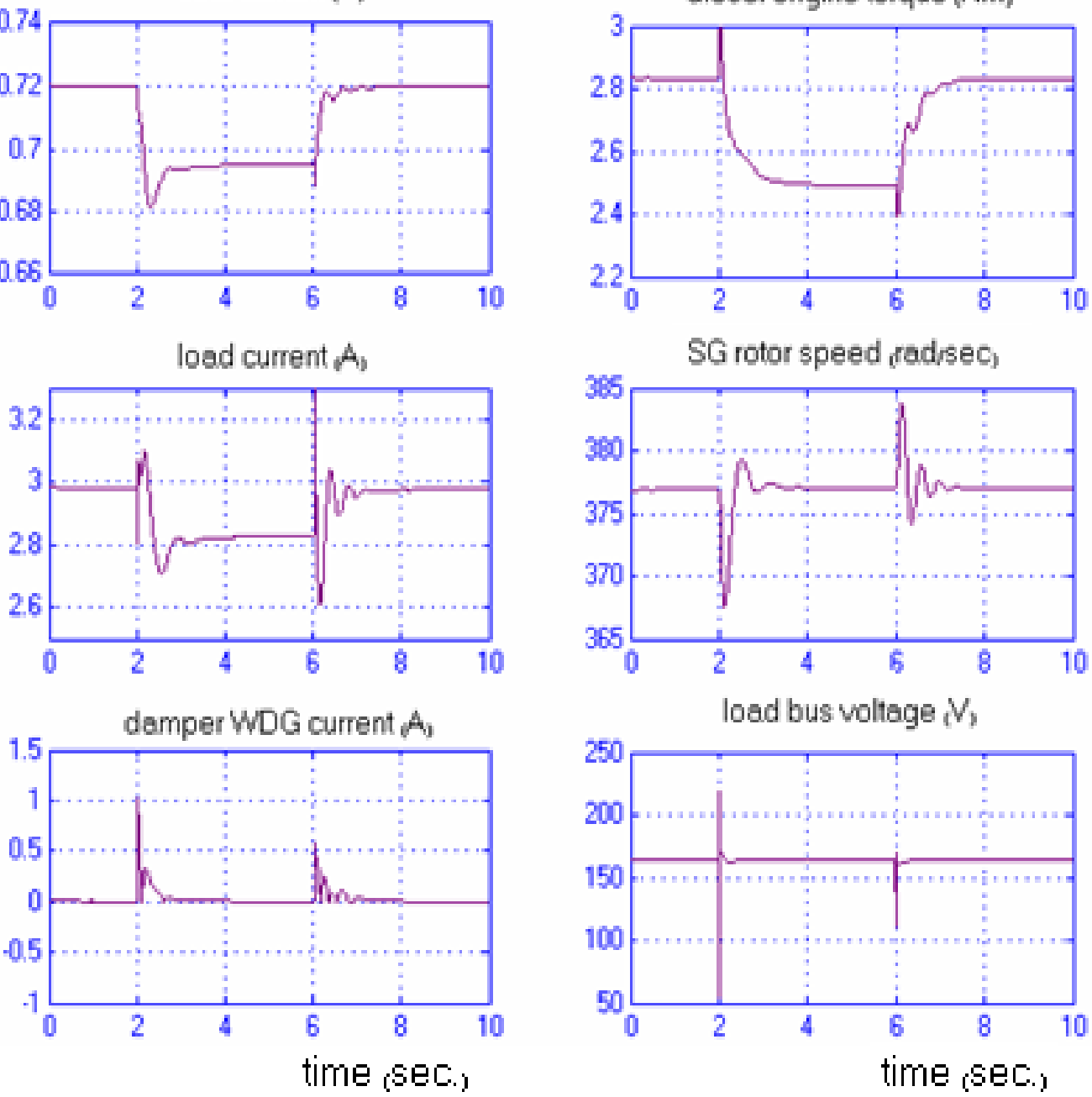

Fig. 6: Dynamic response of the proposed system with a step change in load impedance. 

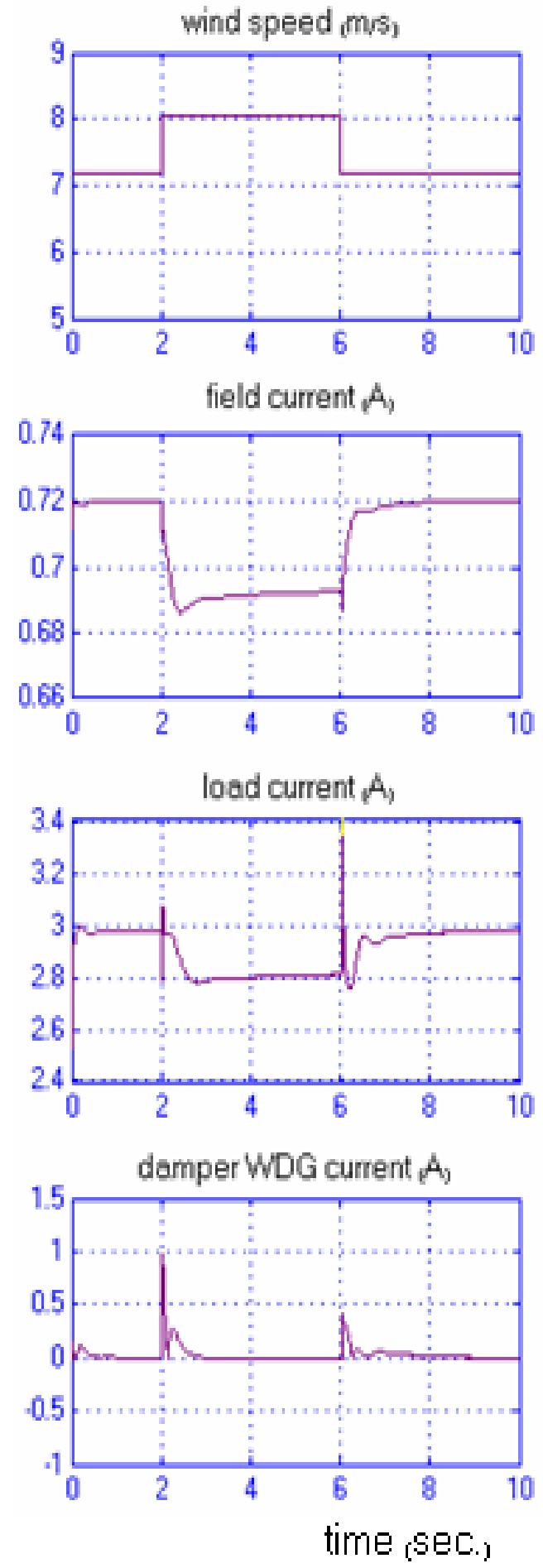
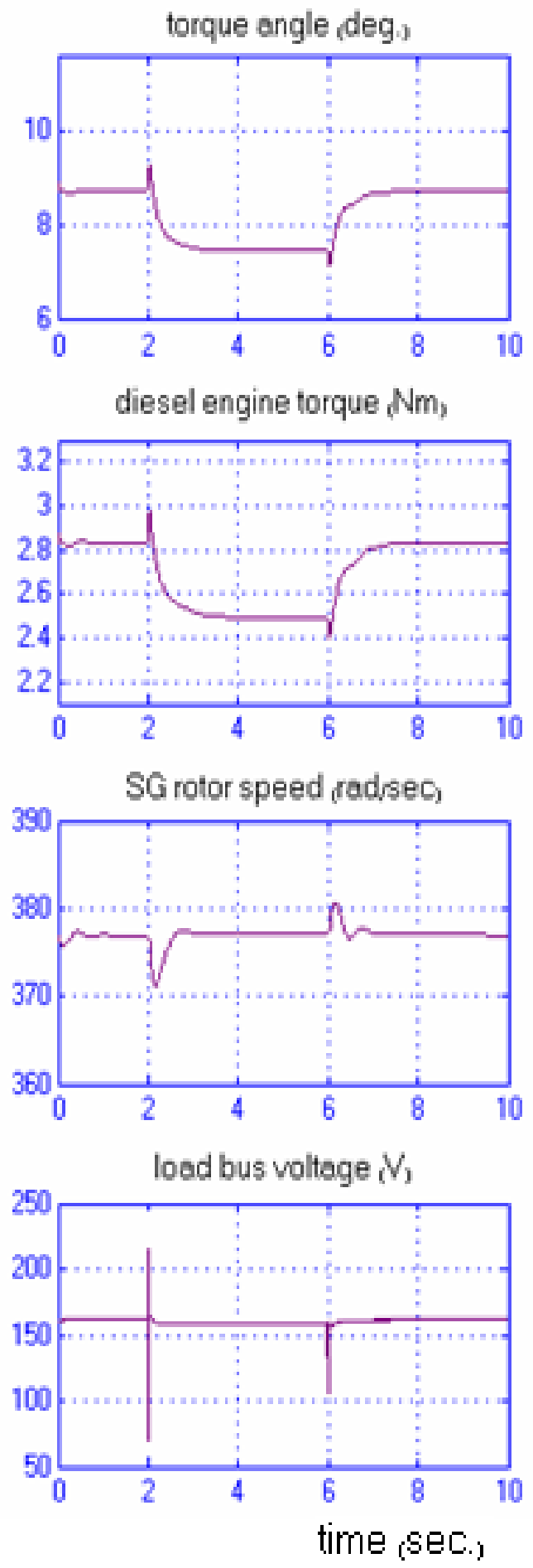

Fig. 7: Dynamic response of the proposed system with a step change in wind speed. 
Digital simulations have been carried out in order to evaluate the effectiveness of the proposed scheme. The wind-diesel energy system with the proposed controller has been tested through step changes in wind speed and load impedance. The results prove that the proposed controller is successful in regulating the terminal voltage and frequency of a stand alone wind-diesel energy conversion system under wind and /or load execursion.

\section{REFERENCES}

[1] J. T. Bialasiewicz, E. Muljad and S. Drouilhet, "Modular Simulation of a Hybrid Power System with Diesel and Wind Turbine Generation". Presented at Windpower '98 Bakersfield, CA, National Renewable Energy Laboratory, April 27-May 1, 1998.

[2] W.E.Leithead, SA.De La Salle and D. Reardon, "Classical Control of Active Pitch Regulation of Constant Speed Horizontal Axis Wind Turbines", International Journal of Control, Vol.55, No.4, pp.845-876, 1992

[3] Hussein Ibrahim, Adrian Ilinca, Rafic Younès, Jean Perron and Tammam Basbous " Study of a Hybrid Wind-Diesel System with Compressed Air Energy Storage", IEEE, Electrical Power Conference, EPC2007, Montreal, Canada, pp. 25-26, October 2007.

[4] Bansal, R.C., "Automatic Reactive-Power Control of Isolated Wind-Diesel Hybrid Power Systems". IEEE Trans. On Industrial Electronics, V 53. Issue 4, pp. 11161126, June 2006.

[5] G.W.Scott, V.F.Wilreker and R.K.Shaltens, "Wind Turbine Generator Interaction With Diesel Generators on an Isolated Power System" IEEE Trans. on Power Apparatus and Systems, V. PAS-103, No.5, pp.933-937, May 1984.

[6] Bansal, R.C, Bhatti, T.S and Kothari, D.P. " Automatic reactive power control of wind-diesel-micro-hydro autonomous hybrid power systems using ANN tuned static VAr compensator". Large Engineering Systems Conference on Power Engineering, V 7. pp. 182-188. May 2003.

[7] Panickar, PS, Rahman, MS and Islam, S., " A Neuro-fuzzy Model for the Control Operation of a Wind-diesel-battery Hybrid Power System". Journal of Electrical \& Electronics Engineering, V 22, Issue 1, pp. 9-16, Australia, 2003.

[8] JURADO Francisco and SAENZ José R., "Neuro-fuzzy control for autonomous wind-diesel systems using biomass". Journal of Renewable Energy, V 27, Issue , 1,pp. 39-56, September 2002.

[9] Chedid, R.B.; Karaki, S.H.; El-Chamali, C. "Adaptive fuzzy control for winddiesel weak power systems".IEEE Trans. on Energy Conversion, V 15, Issue 1, pp. 71-78, Mar 2000.

[10] Pena, R., Cardenas, R., Proboste, J., Clare, J. and Asher, G. "A hybrid topology for a variable speed wind-diesel generation system using wound rotor induction machines". Industrial Electronics Society, 2005. IECON 2005. 31st Annual Conference of IEEE, 6-10 Nov. 2005.

[11] A. Abdin and X. Wilson, " Control design and dynamic performance analysis of a wind turbine-induction generator unit", IEEE Trans. On Energy Conversion, Vol. 15, No. 1, March, 2000, pp 91-96. 
[12] R. M. Hilloowala, “ Control and interface of renewable energy systems”, Ph.D. Thesis, The University of New Brunswick, Canada, 1992.

\section{Appendix}

Synchronous Machine parameters:

Rating: $2 \mathrm{KW}, 208 \mathrm{~V}$ (line), $9 \mathrm{~A}, 4$ pole, Unity power factor.

Constants: $\mathrm{R}_{\mathrm{s}}=0.88 \Omega, \mathrm{R}_{\mathrm{f}}=67.0 \Omega, \mathrm{L}_{\mathrm{md}}=58 \mathrm{mH}, \mathrm{L}_{\mathrm{mq}}=24.9 \mathrm{mH}, \mathrm{L}_{\mathrm{lsd}}=\mathrm{L}_{\mathrm{lsq}}=2.92 \mathrm{mH}$, $\mathrm{L}_{\mathrm{ldd}}=2.92 \mathrm{mH}$

$\mathrm{N}_{\mathrm{se}}: \mathrm{N}_{\mathrm{fd}}=0.047: 1$

$\mathrm{N}_{\mathrm{se}}: \mathrm{N}_{\mathrm{kd}}=2.95: 1$

$\mathrm{N}_{\mathrm{se}}: \mathrm{N}_{\mathrm{kq}}=2.95: 1$

Wind turbine :

Rating: $1 \mathrm{kw}, 450 \mathrm{rpm}$ ( low speed side) at $V_{w}=12 \mathrm{~m} / \mathrm{s}$.

Size $\quad$ : Height $=4 \mathrm{~m}$, Equator radius $=1 \mathrm{~m}$, Swept area $=4 \mathrm{~m}^{2}, \rho=1.25 \mathrm{~kg} /$ $\mathrm{m}^{2}$.

Induction machine :

Rating: $\quad 3$-phase, $2 \mathrm{kw}, 120 \mathrm{~V}, 10 \mathrm{~A}, 4$-pole, $1740 \mathrm{rpm}$.

Parameters : $R_{s}=0.62 \Omega, R_{r}=0.566 \Omega, L_{s}=L_{r}=0.058174$ H. , $L_{m}=0.054 \mathrm{H}$, $J=0.0622 \mathrm{~kg} \cdot \mathrm{m}^{2}$,

$$
f=0.00366 \text { N.m./rad/s. }
$$

DC Link : $\quad R_{D C}=1.7 \Omega, L_{D C}=0.15 \mathrm{H} .$,

Self Excitation Capacitor:

Rating: $176 \mu f /$ phase, $350 \mathrm{~V}, 8 \mathrm{~A}$. 


\section{التحكم المتين في منظومة قوي كهربية للرياح والغاز المعزولة باستخدام منظم جاوسان الخطي}

تزايدت الاهتمامات في السنوات الاخيرة الي استخدام الطاقة الجديدة والمتجددة في توليد الطاقة الكهربية وخاصة من طاقة الرياح خاصـة في المناطق النائية والتي يصسب ربطها بالثبكة الكهربية. ونظرا لعدم ضمان استمرار الرياح او عدم ضمان استمرار الطاقة الكهربية الكافية المولدة من طاقة الرياح لذلك نلجأ الـي انظمـة التوليـد المختلطـة. يتعـرض هـذا البحـث الـي اسـتخدام التحكم التربيعسى الخطـى لجـاوس وذلك في تغذية حمل معزول (غير مربوط بالثبكة (Linear Quadratic Gaussian Control) الكهربية) من نظام توليد كهربي مختلط مكون من وحدتي توليد للكهرباء. الوحدة الأولي مكونة من مولد حثي مدار بتوربينة رياح ومتصل بالحمل من خلال (DC-Link) غير محكوم للحصول علي أقصي قدرة يمكن توليدها من طاقة الرياح. والوحد الثانية مكونة من مولد منزامن مدار بمحرك ديزل. تم تمثيل النظام بنموذج رياضي غير خطي تم توصيفه وتحوبله إلي نموذج رياضي خطي حول نقطة تشغيل محددة مسبقا. تم تثبيت الجهد والتردد علي أطراف الحمل وذلك بالتحكم في جهذ وتردد خرج المولا المتزامن بالتحكم في جهد تغذية ملفات المجال والتحكم في السرعة الدورانية للمولد المتزامن علي التوالي وذلك باستخدام التحكم التربيعى الخطى لجاوس في هذه الطريقة يتكون هيكل الحـاكم من جزئين اساسيين هما : مرشح كالمان (Kalman Filter) ، والكسب المثالي لمتغيرات النظام • وقد تم استخدام مرشـح كالمـان فى تقدير جميع متغيرات النظام المحكوم وضـربها في الكسب المثالي لإيجاد الإشارة الحاكمة. هذه الإشارة يتم إضافتها إلى النظام المحكوم باستخدام التغذية العكسية. وقد تم استخدام إثنارة تيار العضو الثابت لكل من المولد الحثى والمولد المتزامن كدخل لمرشّح كالمان لأنه من السـل

قياسها واستخدم المرشح فى تقدير باقي منغيرات النظام والتى يصعب قياسها.

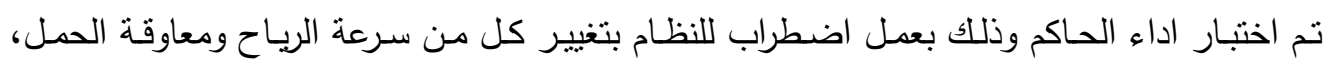
وبحساسيته وقوته ضد تغير قيم بيانات النظام. 